\title{
AS FRONTEIRAS ENTRE NAÇÃO E AMIZADE
}

\author{
nas cartas a um amigo alemão de Albert Camus
}

\author{
Pedro Gabriel de Pinho Araújo \\ Mestrando em Filosofia na Universidade de Brasília - UnB
}

\section{RESUMO}

Uma reflexão a respeito da interação entre os conceitos de nação, justiça e amizade dentro da obra de Albert Camus, sobretudo através do livro Cartas a um amigo alemão. Nela, exploraremos diferentes formas de identidade nacional através da perspectiva da ideia de amor ao país. Para tanto introduziremos a discussão relativa a meios e fins na esfera política com a obra Os Justos. Dessa forma nos aproximaremos das consequências da incondicionalidade de tal sentimento. Finalmente, defenderemos junto a Camus que a justiça deve ser um elemento condicionador nessa relação. Concluiremos a presente discussão com uma breve reflexão a respeito das possibilidades em torno das identidades transnacionais.

Palavras-chave: Camus, nação, justiça, meios e fins, amizade, revolta, amor.

\begin{abstract}
A reflection on the interaction between the concepts of nation, justice and friendship in the works of Albert Camus, particularly through the book Lettres à un ami allemand. Here, we will explore different forms of national identity through the idea of love of the country. Therefore we introduce the discussion about means and ends in politics with the work Les Justes. That way we will approach the consequences of unconditionality of such feelings. Finally, together with Camus, we will argue that justice must be a conditioning element in this relationship. We will conclude this discussion with a brief reflection about the possibilities surrounding the transnational identities.
\end{abstract}

Key words: Camus, nation, justice, means and ends, friendship, revolt, love.

Nos tempos ingênuos em que o tirano arrastava a cidade para a sua maior glória; em que o escravo acorrentado à biga do vencedor era arrastado pelas ruas em festa; em que o inimigo era atirado às feras diante do povo reunido, diante de crimes tão cândidos, a consciência conseguia ser firme, e o julgamento, claro. Mas os campos de escravos sobre a flâmula da liberdade, os massacres justificados pelo amor ao homem pelo desejo de super-humanidade anuviam, em certo sentido, o julgamento.

O Homem Revoltado 


\section{Introdução}

O presente trabalho busca, em primeiro lugar, possíveis contribuições que o escritor (de $O$ ) Estrangeiro poderia oferecer à discussão acerca do conceito da identidade nacional. Tal busca será feita na obra Cartas a um amigo alemão (1948) de Albert Camus. Nesta obra, a identidade nacional é sempre posta em relação ao conceito de amizade. Portanto, também através da reflexão sobre a amizade procuraremos estabelecer como esta relação é posta nesta obra, que convencionaremos de chamar de Cartas e de modo geral na obra deste autor.

$\mathrm{O}$ ato de delimitar um tema, especialmente no caso da questão nacional, está em relação direta com estabelecer fronteiras. Com o auxílio de outro autor argelino, Derrida, poderíamos dizer que, assim muitos de nós que descobrimos o que temos de mais brasileiro (alemão, francês ou o que seja) quando viajamos ao exterior, notamos a importância das margens desta questão. $\mathrm{O}$ estrangeiro surge então como ponto de reflexão privilegiado em nossa questão, pois ele é justamente aquele que está já desde o início inscrito nesse ponto de reflexão, dado que uma análise sobre a identidade nacional feita por um estrangeiro deve necessariamente começar pelas fronteiras.

Camus é um autor fundamentalmente estrangeiro, não apenas pelo título do que é considerada a sua maior obra. Também não só por ser um pied noir, um filho de imigrantes franceses que nasce na Argélia, mas volta à terra natal de seus pais. Não só porque é comumente colocado entre os moralistes ${ }^{1}$, ensaístas que por ter um estilo marcado pela hesitação entre uma demanda referencial de objetividade e o horizonte subjetivo das representações, situam-se nas fronteiras entre a filosofia e a literatura. Mas, sobretudo, por suas reflexões sobre o Absurdo, o conceito fundamental em sua obra que busca expressar o insolúvel exílio de um homem e sua vida. Descobrimos aqui um daqueles raros pontos de vista nos quais as paisagens, às vezes muito distantes, da vida e da obra de um autor se encontram e será a partir desse ponto que estabeleceremos o horizonte do presente trabalho.

As relações entre amor e justiça também constituirão um tema central no presente trabalho, dado que, em Camus, integram um único conceito. Este, juntamente aos conceitos de Absurdo e Revolta, constituem de fato os três temas centrais de sua obra. O amor aqui, não por acaso, trataremos como sendo da mesma espécie que Aristóteles chamará de amizade (philia) no livro VIII de Ética à Nicômacos ${ }^{2}$ e, nesse sentido preciso, também usarei ambas as

\footnotetext{
${ }^{1}$ Classificação compartilhada, por exemplo, por Manuel da Costa Pinto em seu livro sobre Camus, O Elogio do Ensaio (1998).

2 Onde, também não por acaso, ele fará a clássica relação entre Amizade, Justiça e Estado.
} 
palavras para tratar um mesmo conceito.

\section{Além dos Vícios e Virtudes}

Quando as Cartas foram escritas, as fronteiras eram empurradas de todos os lados pelos exércitos da Segunda Guerra Mundial. Enquanto a questão nacional surge na Europa com o início da modernidade, começamos nossa reflexão com o que é considerado o fim desse período. O fim da modernidade aqui é visto como este momento em que o ideal moderno é levado às suas últimas consequências (ARENDT, 1973, p. 12). Podemos notar, já na declaração do amigo alemão que abre Primeira Carta, como esse foi o momento histórico em que a nação foi levada ao seu máximo limite: “A grandeza do meu país não tem preço. Tudo o que a sirva é bom. E num mundo em que nada mais tem sentido, aqueles que como nós, jovens Alemães, tiveram sorte de encontrar um sentido no destino da sua nação, devem sacrificar-lhe tudo" (CAMUS, 2003, p.17). Mas Camus sempre foi estranho à busca de um sentido $^{3}$, especialmente um que exija um sacrifício tão extremo. Vemos aqui o sentido da frase de Pascal que Camus escolhe como epígrafe das Cartas: "Não mostramos grandeza por nos situarmos a um extremo, mas por tocar, ao mesmo tempo, as duas extremidades."

Pascal é provavelmente uma das maiores influências intelectuais de Camus, mas podemos buscar origens mais remotas desta que será a via de formulação da resposta à declaração do amigo alemão. Esse ideal de evitar os extremos parece ser precisamente a fórmula de excelência moral proposta por Aristóteles no Livro II da Ética à Nicômacos. Entretanto, a ideia de tocar os dois extremos parece ir além do jogo entre vícios e virtudes, que tem por objetivo apenas evitar os extremos. Vejamos como a questão é colocada pelas Cartas. Chegamos à pergunta de como, dentro desse jogo pascaliano, poderíamos tocar de fato os dois extremos da questão nacional.

Aqui somos conduzidos pelo autor, ainda na Primeira Carta, à questão da philia, a qual se refere repetidas vezes como "amor ao país" (Ibidem). É dentro desta relação patética 4 com a nação que se estabelecerão as posições do discurso camusiano. Os dois extremos, que como poderíamos imaginar, são negados pelo autor e estão ambos inscritos na declaração desesperada do amigo alemão. Mas, antes de prosseguirmos, faz-se necessária uma pequena

\footnotetext{
3 Lembrando, por exemplo, que a grande questão do Mito de Sísifo (1942) é, dado o Absurdo - que representa justamente a falta de sentido inerente da existência humana - como é possível continuar vivendo.

4 Não no sentido usual, mas de $\pi \alpha \theta \eta \tau \imath \kappa o ́ \varsigma$ (pathetikós), relativo à emoção.
} 
ressalva com relação identidade deste amigo. No prefácio à edição italiana ${ }^{5}$, Camus tenta esclarecer uma questão fundamental à compreensão desta obra: a Alemanha que Camus se refere é ainda claramente a Alemanha Nazista. Trata-se, portanto da refutação da atitude que fez com que o social-nacionalismo alemão levasse o conceito de nação às últimas consequências.

Desta forma, a Primeira Carta começa com a confrontação de duas formas possíveis de amor ao país. A do amigo alemão, que é representada pelo imperativo de "sacrificar-lhe tudo". Do outro lado temos a forma do amor (ou, no caso, não-amor) que surge da acusação do amigo alemão a Camus: "você não ama seu país". Tal acusação nasce da negação de Camus ao imperativo do amor incondicional, tal como é defendido pelo amigo, feita na forma de certas exigências. Essas podem ser brevemente sintetizadas na injunção "amar meu país amando ao mesmo tempo a justiça”. Sendo o amor sem limites um ponto e a negação desse amor por determinadas razões o seu oposto (aqui, é importante notar que se trata de um movimento racional - da inteligência). O meio termo, portanto, surge justamente nesse ponto limítrofe entre a aceitação e a negação que se localizam justamente em um "amor exigente", ou que talvez o amigo alemão chamasse de "condicional". A condição aqui é evidentemente a razão e o amor incondicional exige seu sacrifício: a história perde qualquer sentido para além do acaso da força.

Mas para Camus "há qualquer coisa que conserva um sentido" (Ibidem, p. 29). Essa aparente contradição do autor que declarava a existência absurda (sem sentido), introduz na verdade a virada fundamental do conceito de Revolta. Este conceito é produto do esforço pelo qual Camus buscou justificar porque um regime como o fascista, apesar dos pontos comuns explicitados acima, não poderia clamar para si o título de Absurdo (no sentido estrito camusiano). Além disso, a reflexão absurda é instaurada no plano da subjetividade individual - do privado, digamos assim - e é no plano da Revolta que Camus traz o coletivo - a esfera pública - à sua reflexão. Notamos aqui que tanto Camus quanto o amigo alemão parecem compartilhar esse desespero da inteligência causado pelo Absurdo, mas o amigo comete o "suicídio filosófico" 6 quando abre mão da Revolta contra o Absurdo. A resposta à aparente contradição está na Quarta Carta, quando Camus afirma: “Continuo a pensar que este mundo não tem qualquer sentido superior. Mas sei que nele, se alguma coisa tem sentido é o homem, porque é ele o único a exigi-lo" (Ibidem, p.52). Esse "sentido do homem" é configurado

\footnotetext{
${ }^{5}$ A primeira publicada fora da França e que surge alguns anos depois do fim do conflito.

6 O Suicídio Filosófico é um conceito exposto no capítulo de mesmo nome de $O$ mito de Sísifo e é, resumidamente, a rendição ao Absurdo, quando a inteligência se desespera frente à falta de sentido do mundo e de forma ou outra cessa a luta contra ele.
} 
justamente na forma de uma fraternidade de toda a humanidade e é essa razão pela qual, mesmo dadas as circunstâncias, Camus refere-se a seu interlocutor como o "amigo alemão". Deveriam ser inimigos, "mas alguns de nós sentem ainda bem quanto são parecidos com os outros homens, para aceitarem tal opção" (Ibidem, p.128), pois "também sei o que nos une, e o que cada um deles possui, que faz com que não possa desprezá-los sem me desprezar a mim mesmo" (Ibidem, p.98). Aqui somos redirecionados à questão da philia.

Este amor ao país que também pressupõe a amizade entre os homens é de uma coerência de oposição impressionante ao ponto de vista nazista que só poderia se permitir aplicar sua lógica de conquista quando pressuposta a "superioridade racial". Ou seja, a posição do amigo/inimigo alemão abre mão não apenas da justiça, mas da igualdade (e nesse sentido da philia) entre os homens ${ }^{7}$. Podemos dizer, portanto que é precisamente essa philia aquilo que ainda tem qualquer sentido para Camus ${ }^{8}$. Foi por esse sentido que, segundo ele, os franceses ${ }^{9}$ pagaram e o fizeram à custa da eficiência. Do outro lado, o regime nazista, como podemos constatar, foi propriamente um regime de culto à eficiência. Temos aqui o pressuposto fundamental que separa o amor incondicional do amigo alemão e o amor exigente de Camus.

\section{Amizade entre meios e fins}

Leitores deste autor notarão imediatamente que este é um confronto que marca um ponto fundamental de seu pensamento, as relações entre meios e fins. Essa questão é aparece de forma muito clara em Os Justos de Camus. Inspirada em um episódio que de fato ocorreu na Rússia em 1905, narra o conflito entre dois revolucionários, um que não mede consequências para fazer valer a causa, Stepan, e o outro que mantem sempre seus limites morais, Kalyaiev. Evidentemente, a posição camusiana, que também evidentemente uma de conflito, é representada por Kalyaiev. Podemos ir até o ponto de dizer que Stepan representa a posição sartreana com relação à ação revolucionária, onde os fins podem justificar os meios, como quando ele faz publicamente a justificativa do "o massacre de Munique" nas

$7 \quad$ Aristóteles, na Ética a Nicômacos, discorre sobre a amizade entre desiguais, no entanto deixa claro que uma amizade perfeita desse tipo é impossível. Fica claro que a amizade entre os homens que Camus busca é a amizade entre iguais e aparentemente a única de fato possível.

Referente à aparente contradição do último parágrafo da página 4 do presente trabalho.

9 Entretanto, cabe a ressalva aqui que, apesar de Camus muitas vezes defender nas Cartas posições suas como posições da nação francesa - ato escusável dado as circunstâncias impostas pela Resistência - o próprio autor, no artigo intitulado Contágio, demonstra como os franceses tomaram atitudes semelhantes a dos nazistas. Neste artigo o autor denuncia que os conflitos com as colônias africanas foram marcados por pressuposições de superioridade racial muito semelhantes à do III Reich. 
Olímpiadas de $1972^{10}$. Kalyaiev é escolhido no grupo para assassinar o Grão-Duque Sérgio Alexandrovich, filho do então czar Alexandre II da Rússia e, portanto, importante figura do regime czarista que deve ser derrubado. Sua primeira tentativa falha, pois, no momento em que iria colocar uma bomba na carruagem do grão-duque, percebe que ele está acompanhado de seus sobrinhos, o que o faz desistir. Sua segunda tentativa é de sucesso, mas ele é preso e jogado na prisão.

No nosso caso, o ponto de confronto dá-se aqui precisamente na afirmação do amigo alemão de que "A grandeza do meu país não tem preço" $"$. Camus não disputa que alguma grandeza seja alcançável com “campos de concentração e fábricas de morte”, mas seu preço é justamente a justiça. Para ele, ao contrário, é a Justiça que não tem preço e nada, nem a felicidade ou grandeza de um povo, é urgente o suficiente para o seu sacrifício.

Mas a que tipo de Justiça nos referimos aqui? Esse termo assume uma polissemia peculiar em Camus. Por um lado temos a noção de justiça presente já em O Estrangeiro. Lá ainda vemos um jovem Camus e sua defesa dos subalternos. Em uma descrição negativa, vemos a forma que a justiça tradicional se configura em seu oposto, ou, como afirma Licoln:

De fato, a justiça tradicional é identificada dentro da obra camusiana como um sistema de exclusão, diretamente ligado a um desejo de poder e fundado sobre a normalização daqueles que são 'separados', 'marginalizados' relativamente às exigências da norma. (LINCOLN, 2010, p.77)

Outra forma inversa de justiça rejeitada aqui é aquela pela qual Camus foi muito criticado, quando disse: "Eu acredito na justiça, mas defenderei minha mãe antes da justiça." ${ }^{12}$.Ele se referia ali ao terrorismo cego exercido nas ruas durante a guerra da Argélia. Camus era contra a opressão colonial do poder francês ${ }^{13}$, mas, de maneira um pouco contra popular, não estava disposto a admitir a justiça cega que plantava bombas em cafés pela sua cidade natal. Enfim, voltamos à discussão entre meios e fins, em que uma boa causa não pode justificar uma atitude bárbara.

Voltando à dinâmica proposta pelos personagens centrais de Os Justos: Stepan, esse artesão da revolução, sabe precisamente o que fazer para levar essa a cabo. Mas a recomendação aristotélica de não esperar a mesma precisão no campo ético que na

10 Quando afirma: "terrorismo é uma arma terrível, mas o pobre explorado não tem nenhuma outra" (tradução minha) em SARTRE, Jean-Paul. La cause du peuple. Número 29, outubro de 1972.

11 Primeiro parágrafo da primeira carta de Cartas a um amigo alemão.

12 Em dezembro de 1957, em discurso na Maison des étudiants de Estocolmo.

13 A postura de Camus com relação aos conflitos na Argélia eram complexos e não serão desenvolvidos aqui. Para maiores referências sobre o assunto recomendo a leitura dos Actuelles III. 
matemática, aplica-se aqui: a lei é fundamentalmente geral e por principio incapaz de julgar com precisão cada caso. Aqui o pensamento antigo e contemporâneo repelem em uníssonos uma abordagem técnica da ética: apenas Kalyaiev é capaz da excelência revolucionária, mesmo que essa não alcance êxito e que no final das contas ele tenha que morrer por isso - e talvez precisamente por isso ele seja capaz de tal excelência.

Amar o país aqui parece ser definido, sobretudo, em termos de desejar-lhe a grandeza $^{14}$, isso poderíamos dizer que ambas as posições têm em comum. Mas a diferença óbvia é que a preocupação com a grandeza do amigo alemão é restrita à questão da quantidade - é precisamente nesse sentido que se desenvolve o pensamento "A grandeza do meu país não tem preço”. A ausência de valor extirpa ao mesmo tempo a qualidade. A preocupação com o tipo de grandeza é ao mesmo tempo a preocupação com a qualidade desta e neste sentido se dá a recusa a uma "grandeza qualquer". Aqui fica clara a acusação que Camus faz de que tal posição se arvora em um "culto à eficiência", que é um tema em si muito interessante, mas que não encontra espaço suficiente na presente discussão.

É a partir desse ponto que Camus, na Segunda Carta, retoma a acusação "você não ama o seu país”. O culto à eficiência aqui é tomado como certo tipo de desprezo da inteligência, no sentido que a ação que não questiona seus pressupostos sempre se dá em uma forma de "salto de fé". Tal movimento, em uma perspectiva mais política, é mais extensamente analisado em $O$ Homem Revoltado (1951), onde percebemos a condenação do autor a qualquer posição que sacrifique o presente em função da realização de um ideal histórico (condenação essa, portanto, que se aplica a qualquer regime totalitário e não apenas ao nazismo). Claro que existiram "teóricos do nazismo" de várias espécies, mas a defesa de tal regime, a partir do momento que são levadas em conta também as suas ações mais extremas, deve necessariamente partir de uma negação do presente. Essa negação baseia-se em uma aposta no futuro, dada a sua incerteza inerente (tanto com relação à sua efetividade material - o como - quanto temporal - o quando). Ou seja, o "culto à eficiência" é precisamente o "reino dos fins", a consequência necessária de uma grandeza sem preço.

A Terceira Carta abre com a declaração "As palavras tomam sempre a cor dos actos ou dos sacrifícios que suscitam" (CAMUS, 2003, p. 39) e daí prossegue para a definição do termo comum: Europa. Digo termo comum no sentido que, dada a direção discursiva que Camus apresenta em todo o livro, é claro o desejo comum de alguma espécie de unidade

\footnotetext{
${ }^{14}$ E aqui notamos grande influência nietzschiana, tanto na sua corrupção por parte do Regime Nazista, quanto pela apropriação característica feita por Camus. O que não é nenhuma surpresa dado que Nietzsche é facilmente identificado como uma de suas maiores influências.
} 
europeia. A diferença, logicamente, está na forma como essa unidade será alcançada e na forma com que ela será configurada. Difícil não dizer, que ao fim e ao cabo, nesse momento histórico a Alemanha buscava apenas o domínio completo. Do outro lado Camus fala de uma "pátria maior" (CAMUS, 2003, p. 44), a aventura comum do homem ocidental. Como uma peça retórica, é de se esperar que ele não indicasse a não ser de forma escassa o que viria a ser uma pátria maior. Mesmo assim, gostaria de insistir nesse ponto dado que acredito ser um ponto relevante para a questão nacional.

Tal identidade transnacional, que liga a história comum de um continente, ou às vezes além disso, aparece aqui como consequência direta das duas posições extremas expostas no início do trabalho. A questão da identidade europeia ainda é um assunto quente e, como o autor previu “A Europa ficará ainda por fazer" (Ibidem, p.45), mas, mesmo no debate contemporâneo sobre essa questão, podemos notar, por um lado, aqueles que buscam uma integração cada vez maior, baseados em pontos comuns (a princípio econômicos, mas depois históricos e culturais); e aqueles que resistem, baseados no temor da dissolução da identidade nacional. Deixemos a questão da globalização e voltemos ao cenário europeu (mesmo que a Grande Guerra seja também mundial). Seria possível aqui, voltando à formula pascalina, tocar os dois extremos? Parece-me que isso já é feito, ao menos na forma de ensaio, por meio das regulações internacionais, que, compreensivelmente, ainda estão em um estado infantil.

Sabemos ser um truísmo falar que uma discussão séria nesse sentido é inevitável. Mas a essa altura, depois disso que podemos chamar de um inverno das nações, a questão nacional deve ser revista com cuidado. As políticas internacionais contemporâneas ainda parecem apenas reforçar os velhos modelos e tensões de cunho nacional e continuam a aparecer da mesma forma, diferindo apenas com o crescente potencial destrutivo.

Como afirma Camus: "a tragédia hoje é coletiva" (Ibidem, p.122). Não acredito que o mundo possa ser unificado "por cima" como acredita o autor, por um Estado mais poderoso que todos os outros (Rússia e Estados Unidos na época). Mas essa possibilidade ainda deve ser confrontada. Voltemos à questão da globalização: não existe o risco de que isso seja apenas uma espécie de americanização? Mas falamos aqui de conquistas culturais, o que é assustador. Sorte nossa se pudéssemos temer apenas a possibilidade de que não demos tempo suficiente ao prognóstico de Marx, para o qual a ordem internacionalizante do capital dissolveria as nações. Mas parece sintomático esse temor, também expresso por Camus no que trata a unificação feita "por cima", quando ele diz "Detesto essa ideia como francês, $e$ ainda mais como mediterrânico" (Ibidem, p.123). Perguntar pela origem desse temor parece indicar já esse contra movimento que surge com toda força unificadora. Um ótimo exemplo é 
o que acreditamos ser o malogro da profecia de Marx: a explosão do nacionalismo em diversos países europeus e o resultado final do que se convencionou chamar Primavera das Nações ${ }^{15}$. Mas as grandes manifestações contemporâneas parecem nos dizer que ainda é muito cedo para se ter certeza.

\section{Referências Bibliográficas}

ARENDT, Hannah. As origens do totalitarismo - Parte II: Imperialismo. Tradução de

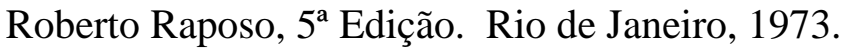

ARISTÓTELES. Ética a Nicômacos, tradução de Mário da Gama Kury, 4a Edição. Brasília: Editora Universidade de Brasília, 2001.

CAMUS, Albert. Cartas a um amigo alemão, tradução de José Carlos González e Joaquim Serrano, $1^{a}$ Edição. Lisboa: Editora Livros do Brasil, 2003.

O Mito de Sísifo, tradução de Ari Roitman e Paulina Watch. Rio de Janeiro: Editora Record, 2004.

. Os Justos, tradução de António Quadros, coleção miniatura. Lisboa: Editora Livros do Brasil, s/d.

O Homem Revoltado, tradução de Valerie Rumjanek, $6^{\mathrm{a}}$ edição. Rio de Janeiro: Editora Record, 2005.

Gallimard, 1958.

Actuelles III, Chronique Algérienne (Chroniques 1939-1958). Editora

LINCOLN, Lissa. "L'éthique de l'artiste révolté". Revista Synergies Inde. American University of Paris, Número 5, 2010. Páginas 75-85.

PINTO, Manuel da Costa. Albert Camus - um elogio do ensaio. São Paulo: Ateliê Editorial, 1998.

\footnotetext{
${ }^{15}$ Série de eventos também conhecidos como Revoluções Européias de 1948, marcada, dentre outras coisas, por notável aumento no nacionalismo de diversos países.
} 